\title{
A SEASON FOR VIOLENCE
}

\section{THE LYNCHING OF BLACKS AND LABOR DEMAND IN THE AGRICULTURAL PRODUCTION CYCLE IN THE AMERICAN SOUTH*}

SUMMARY: In this paper we explore the hypothesis that monthly variation in white mob violence against blacks in the American South was affected by seasonal variation in the demand for labor in southern agriculture. Using monthly data on black lynchings that occurred between 1882 and 1930 we find that mob violence was more frequent during times of stronger labor demand than during slack periods. While the manifest function of lynchings might well have been to rid the white community of offending blacks who violated the moral order, we suggest that the latent function was to tighten the reins of control over the black population, especially during times when whites most needed black labor to work fields of cotton or tobacco.

\section{Introduction}

Between 1882 and 1930 the American South witnessed over 2,000 incidents of lynch mobs hanging, shooting, burning, or otherwise murdering over 2,400 black men, women, and children. ${ }^{1}$ Many explanations have been offered as to why the rule of law was subverted and the citizenry resorted to extra-legal mob violence. Some of the most common explanations include: white reaction to distorted perceptions of black-on-white crime, the need for whites to maintain terroristic control over the black population, the exaggerated fears of whites of a black political or economic threat, or the displaced aggression of the white lower class directed toward the disenfranchised and largely powerless black population. ${ }^{2}$

* This research was partially funded by grants from the National Science Foundation (SES-8618123), and the University of Georgia Research Foundation.

${ }^{1}$ For our purposes in this paper the "South" is defined as Alabama, Arkansas, Florida, Georgia, Kentucky, Louisiana, Mississippi, North Carolina, South Carolina, and Tennessee. Our definition of a lynching closely follows the one adopted by the National Association for the Advancement of Colored People: (1) there must be evidence that a person was killed; (2) the death must have been illegal; and (3) a group of at least three conspirators must have participated in the killing. See National Association for the Advancement of Colored People. Thirty Years of Lynching, 1889-1918 (New York, 1969). Thus we differentiate between a racially-motivated murder which could be committed by a single assassin and a lynching which had to be conducted by a group.

${ }^{2}$ See E.M. Beck and Stewart Tolnay, "The Killing Fields of the Deep South: The 
Previous work has tried, with varying degrees of success, to explain spatial variation in lynchings, as well as trends in lynching activity over extended periods of time. In this research we examine one neglected, but nevertheless interesting, aspect of southern lynchings: the seasonal periodicity of anti-black mob violence, and by "periodicity" we mean any intraannual periodic variation in lynching activity. The basic questions we seek to answer are: (1) is there any evidence of a seasonal periodicity in mob violence against blacks, (2) if so, can this variation be explained by a more general seasonal pattern of violent crime in the South, and (3) if not, can the seasonality be tied to the cycle of agricultural production?

\section{The seasonality of southern lynchings and its meaning}

An assumption that the intensity of mob violence varied with the seasons has long been part of the conventional wisdom of mob violence. ${ }^{3}$ For example, in 1932 the Southern Commission on the Study of Lynching noted that lynchings were most prevalent in the summer months. They provided two possible explanations for this pattern. First, they blamed the idleness of the rural population during the summer months when the cotton crop was maturing and awaiting harvest.

During the midsummer months, after cultivating is done and before harvesting

Market for Cotton and the Lynching of Blacks, 1882-1930", American Sociological Review, 55 (1990), pp. 526-539; Hubert M. Blalock, Toward A Theory of Minority. Group Relations (New York, 1967); Jay Corzine et al., "Black Concentration and Lynchings in the South: Testing Blalock's Power-Threat Hypothesis", Social Forces, 61 (1983), pp. 774-796; Jay Corzine et al., "The Tenant Labor Market and Lynching in the South: A Test of Split Labor Market Theory", Sociological Inquiry, 58 (1988), pp. 261-278; Carl I. Hovland and Robert R. Sears, "Minor Studies of Aggression: Correlations of Economic Indices with Lynchings", Journal of Psychology, 9 (1940), pp. 301-310; James M. Inverarity, "Populism and Lynching in Louisiana, 1889-1896: A Test of Erikson's Theory of the Relationship Between Boundary Crises and Repressive Justice”, American Sociological Review, 41 (1976), pp. 262-280; Alexander Mintz, “A Re-Examination of Correlations Between Lynchings and Economic Indices", Journal of Abnormal Social Psychology, 41 (1946), pp. 154-160; John Shelton Reed, "Percent Black and Lynching: A Test of Blalock's Theory", Social Forces, 50 (1972), pp. 356-360; Stewart Tolnay and E.M. Beck, "Black Flight: Lethal Violence and the Great Migration, 1900 to 1930", Social Science History, 14 (1990), pp. 347-370; Stewart Tolnay and E.M. Beck, "Racial Violence and Black Migration in the South, 1910 to 1930", American Sociological Review, 57 (1992), pp. 103-116; Stewart Tolnay et al., "Black Lynchings: The Power Threat Hypothesis Revisited", Social Forces, 67 (1989), pp. 605-623.

${ }^{3}$ Jesse Ames, The Changing Character of Lynching (Atlanta, 1942), pp. 13-14; Joel Williamson, The Crucible of Race: Black-White Relations in the American South Since Emancipation (New York, 1984), p. 186. 
begins, there is little to occupy the time of Negro and white workers on Southern farms, nearly two-thirds of whom are wage hands or tenants. During the slackwork summer months, there is a great deal of visiting, loafing, gambling, and general "carousing about", and inevitably an unusually large amount of crime. ${ }^{4}$ (emphasis added)

Second, they offer an economic interpretation which stresses the "need" for greater supervision of farm laborers by landlords during the summer months,

[...] relations between landlords and tenants in summer account for an unusually large amount of major strife. During the winter, the tenant is disposed to conduct himself so as to get a "place" for the coming year. With summer, the tenant has received about all he can get from the landlord, and often owes the latter practically all his equity in the crop, a situation that tends to lessen the tenant's industry [...]. Thus, in summer, tenants are likely to be more hopeless and antagonistic and the landlords and their overseers more domineering, than at other periods of the year. ${ }^{5}$ (emphasis added)

Importantly, these two quotations suggest two very different models for the seasonal periodicity of lynching. Is the seasonality of lynchings due to summertime crime, or a reflection of the need to control agrarian black labor? We explore these alternative models, and their implications, below.

\section{The "crime model" of seasonal violence}

The first implied model for the seasonality of lynching stresses the opportunity for mischievous and criminal behaviour by the agrarian labor force when the demands for agricultural work are slack. Within this framework it is possible to assign "responsibility" either to the white or black farm workers. Perhaps idleness during the summer months led to increased criminal activity among black laborers. In response, whites resorted to mob violence to punish black law violators. On the other hand, it is possible that idle and restless whites victimized innocent blacks, in which case the increased criminal activity occurred among white laborers. In either case, this model suggests that lynchings should display roughly the same seasonal pattern as other serious crimes - varying directly with the opportunity for such crimes to be committed.

There is widespread belief that many violent crimes display monthly variation. In fact, as early as the nineteenth century, a seasonal rhythm of

${ }^{4}$ Southern Commission on the Study of Lynching, Lynchings and What They Mean (Atlanta, 1932), p. 12.

${ }^{5}$ Southern Commission, Lynchings and What They Mean, p. 12. 
violent crime had been postulated. ${ }^{6}$ Writing in the early 1840 s, Adolphe Quetelet noted:

The seasons have a well-marked influence in augmenting and diminishing the number of crimes. These differences are readily explained by considering that during winter misery and want are more especially felt, and cause an increase of the number of crimes against property, whilst the violence of the passions predominating in the summer, excites to more frequent personal collisions. ${ }^{7}$

As Quetelet hints, commonly two interacting factors are offered to explain seasonality of violent crimes against persons. First, because of the favorable climate during the summer months, and the greater number of daylight hours available, people are more likely to congregate in social interaction of all types, including conflictual or hostile interactions. Given this situational factor, the second part of the argument is advanced: because of the adverse effects of temperature and humidity on personal disposition, hot, humid weather reduces a person's capacity for coping with stressful conditions and increases irritability. Thus, it is during the summer, with its longer, warmer days, that inter-personal conflict is most likely to occur because of proximity and climatological stress. ${ }^{8}$

While this climatological-social interactionist framework has been rigorously criticized by Cheatwood for both theoretical and empirical inadequacies, there does seem to be empirical evidence indicating some form of periodic (non-random) variation in the frequency of violent crimes. ${ }^{9}$ In particular, homicides are relatively more frequent during July, August, and December. According to a 1980 Bureau of Justice Statistics report on seasonal crime for the period 1973-1977, aggravated assaults peaked in June, fell off somewhat in July, rose again in August, and then declined into the January-February period when assaults were the least common. ${ }^{10}$ Possibly more relevant for our discussion, however, is the Kerner Commission's finding that during the racial unrest of $1967,83 \%$ of the 164 major and minor civil disorders recorded in the United States occurred during the

${ }^{6}$ According to Cheatwood, the history of crime seasonality can be traced back at least to Hippocrates. See Derral Cheatwood, "Is There A Season for Homicide?", Criminology, 26 (1988), pp. 287-306.

${ }^{7}$ Adolphe Quetelet, A Treatise on Man and the Development of His Faculties (New York, 1968), p. 90.

${ }^{8}$ One problem with this theory is that a large number of homicides occur in December as well as in the summer months. Obviously, we can't employ the same kind of climatic argument to December homicides. Furthermore, it could be argued that during the colder months, people tend to be enclosed in close proximity, thus possibly producing stressful conditions favorable for hostile interactions.

9 Cheatwood, "Is There A Season for Homicide?", pp. 287-306.

${ }^{10}$ U.S. Bureau of Justice Statistics, Crime and Seasonality. National Crime Survey Report SD-NCS-N, NCJ-64818 (Washington, 1980). 
summer months, with 103 disorders erupting in July alone. ${ }^{11}$ This kind of evidence suggests that violent behavior - in general - may be more likely in some months than in others, particularly during the summer.

The "crime model" of periodicity in lynching suggests that monthly variation in lynchings, while real, is probably not unique and is a reflection of a more generalized pattern of violence. This implies that if one were to "adjust" any observed monthly pattern in lynching by the corresponding monthly variation in other violent crime, no special "lynching pattern" should remain. On the other hand, if a residual monthly pattern persists after adjusting for the seasonality of violent crime, then we would suspect the operation of other factors unique to lynching.

\section{The "labor control model" of seasonal violence}

The second implied model of the seasonality of lynching argues that landlords and planters were required to exercise greater supervision over their workforce during the summer months. Although the Southern Commission on the Study of Lynching appeared to connect this motive among landlords to the slack agricultural season, we believe that they may have misinterpreted the situation somewhat. Rather, we suggest that landlords were inclined to exercise greater oversight during the periods of most intensive need for labor. And, in contrast to the assertion made by the Commission, cotton cultivation required considerable labor inputs during some summer months.

The agricultural production cycle for cotton set the pace for much of life in the South. ${ }^{12}$ In winter, field hands would break land with mule-driven plows clear last season's cotton stalks, start a compost heap, and prepare the soil for planting. As warmer days arrived in late March and April, cotton seed would be planted; then after sprouting in May, field workers would be set to "chop out" (thinning) cotton plants and weeds with a hoe - a highly labor intensive process that continued until the "lay-by" in midsummer. According to the Southern Cultivator, May was "[...] generally the most tedious and expensive part of the work of cultivation", not only because the cotton "chopping", but also the corn and other crops demand-

11 Otto Kerner et al., Report of the National Advisory Commission on Civil Disorder (Washington, 1968), p. 66.

${ }_{12}$ C.P. Brooks, Cotton: Its Uses, Varieties, Fibre Structure, Cultivation, and Preparation for the Market (New York, 1898), pp. 150-173; Pete Daniel, Breaking the Land: The Transformation of Cotton, Tobacco and Rice Cultures Since 1880 (Urbana, 1985), pp. 3-22; Ulrich B. Phillips, Life and Labor in the Old South (Boston, 1930), pp. 112-115; Rupert B. Vance, Human Factors in Cotton Culture: A Study of the Social Geography of the American South (Chapel Hill, 1929), pp. 150- 173. 
ed attending as well. ${ }^{13}$ By late July or early August the most intensive work was completed and the cotton crop would be "laid-by", meaning that the bulk of the fieldwork was finished until early fall, and there was now time for more relaxed activities. In September the hand picking would begin and continue through November until all bolls had burst and the fields stripped. After each picking, raw cotton was carted to the gin to be cleaned of seed and baled for market. During the late fall and early winter the fields would again lay fallow, until it was time to start the next season's plowing. Not coincidentally, it was during this slack time that travelling carnivals, fairs, and tent-shows visited Dixie - taking advantage of fresh "cotton" money in pants' pockets and purses throughout the South. ${ }^{14}$

Thus, in the Cotton culture there were two periods of intense work activity: the first was in the early summer when the cotton had to be chopped and weeded, and the second during the fall harvest. If a labor control model of seasonality is correct, we should expect lynchings to be relatively more frequent during these two periods when labor demand is strong.

The processes hypothesized by the labor control model should operate over and above any underlying monthly pattern which is more or less common to violent crimes in general. Thus, while the summer months may have facilitated increased interaction between the diverse segments of southern society, thereby possibly contributing to an increase in violent crime (including lynching), the efforts by white landlords to control their black labor force should produce a unique seasonal pattern for lynchings. In short, if the labor control model is correct, then a residual monthly pattern to lynchings should persist - even after adjustments are made for the seasonal pattern of other violent crime.

These alternative models for the seasonality of lynching will be evaluated in the empirical analyses to follow, but first we describe the lynching data that we will use.

\section{Data on lynchings in the United States}

Previous investigators of southern lynchings have been forced to rely on problematic inventories of lynching victims. Thus, even the seasonal variation in lynching activity noted by the Southern Commission on the Study of Lynching must be viewed with caution. We have noted elsewhere that the most commonly used inventory of lynchings, that compiled by the National Association for the Advancement of Colored People (NAACP),

13 The Southern Cultivator, or Dixie Farmer, XLIX (1891), Numbers 1-12.

14 Vance, Human Factors in Cotton Culture, p. 306. 
includes numerous errors and omissions. ${ }^{15}$ In the analyses described here, we use a newly created inventory of southern lynchings between 1882 and 1930. A brief description of these new data is in order.

We identified three publicly available sources for data on lynchings: the best known is the inventory compiled by the NAACP covering the years 1889 to 1918 , and the NAACP's annual supplements thereafter. Second, from 1882 through 1918 the Chicago Tribune newspaper published a list of lynch victims in their year-end summaries, appearing early in January of the following year. And lastly, we used a listing compiled by Daniel Williams based on Tuskegee University's newspaper clipping files. ${ }^{16}$ Originally we planned to use these files as cross-checks for accuracy, but learned quickly that there were too many discrepancies among these sources, even though these three sources were not independent. After careful consideration, it became quite clear that none of these sources could be used, together or in isolation, to supply sufficiently reliable data on southern lynchings.

Using these three overlapping sources, we compiled a "master" list of all reported lynching victims, noting the inconsistencies in details among the sources. Next, we tried locating each lynching incident in a local or regional newspaper account. During this "confirmation" process we found that the three sources contained a vast number of factual errors of all descriptions, as well as uncovering some lynchings which had been overlooked by all three. Our final inventory includes only those lynchings which could be confirmed by newspaper account. In this paper, we restrict our analyses to incidents of lynchings which involved at least one black victim.

While these lynching data are not beyond reproach, and are subject to revision when new information is uncovered, we believe that they are the most accurate data on southern lynchings which now exist. All lynch data, however, are subject to criticism that inventories based on newspapers under-count lethal mob violence. This under-count could be created by any one of three situations: (1) if the lynching was unknown to the news media; (2) if the lynching was known, but went unreported either because the event was not considered newsworthy, or because of the fear that publicizing mob violence would reflect negatively on the local community; or (3) if the lynching was reported locally in a small village, but the story was not picked-up by a news service or a larger regional newspaper. We do not believe that the first situation was very common. To be effective in social control, lynchings had to be visible, with the killing being a public spectacle or at least minimally having the corpse on display for all to witness. Whereas a murder - even a racially motivated one - might be hidden from

15 Tolnay et al., "Black Lynchings: The Power Threat Hypothesis Revisited", p. 608; Beck and Tolnay, "The Killing Fields of the Deep South", pp. 530-531.

${ }^{16}$ Daniel Williams, Amid the Gathering Multitude: The Story of Lynching in America: A Classified Listing (Unpublished manuscript, Tuskegee University, 1968). 
public scrutiny, lynchings were not. As for the second argument, through reading the numerous newspaper accounts describing mob violence, it does not appear that newspapers were at all inhibited in reporting morbid and gory details, and often used sympathetic language in describing the lynch mob while reserving callous damnation for the lynch victim. ${ }^{17}$ As for the last issue - obscure lynchings - it is possible that a lynching occurred in some isolated, rural area and that it was never noticed by one of the larger newspapers so was not recorded by the Chicago Tribune, the NAACP, Tuskegee, or our coders. However, given the frequency with which lynchings were reported, we doubt if the number of obscure lynchings is large. ${ }^{18}$ Ayers has also referred to, " $[\ldots]$ the speed and thoroughness with which news of lynchings were spread by the press of the late nineteenth-century South $[\ldots]$ '. ${ }^{19}$

These revised data will first be used to describe the seasonal periodicity of lynching incidents by looking at monthly variation in the reported instances of lynching which had at least one black victim. It should be noted that our analytical focus is on the periodicity of lynching incidents, not the monthly pattern of lynching victims because the latter may create distortions due to some lynching incidents having multiple victims. ${ }^{20}$

\section{The seasonal pattern of anti-black mob violence}

In Table 1 we report the monthly distribution of black lynching incidents for ten southern states, aggregated over the period 1882 through 1930. An inspection of the distribution of lynchings for the entire South (the last column in Table 1), as well as an examination of the distributions for each southern state, shows that there was significant monthly variation and variation across states in the frequency of anti-black mob violence. To

${ }^{17}$ It could be argued, however, that there was a shift in this position after World War I as national anti-lynch campaigns became more vocal and some of the southern business community began to view mob violence as a hinderance to commercial growth.

${ }_{18}$ Rather than a problem of under-count, we believe that a potentially more serious problem with existing inventories is one of reporting error, including the reporting of events which were non-lynching events. The term "lynching" was used to describe a variety of phenomenon, some of which were simple murders and other non-lynchings. In other instances, there were reports of an expected lynching or supposed lynching without sufficient evidence that a killing actually took place. Based on our experience so far, 1 out of 6 previously reported lynching victims failed to meet our definition of a lynching and were excluded from our inventory. All of this leads us to believe that the problem of over-count is as potentially serious as one of under-counting, perhaps even more so.

${ }^{19}$ Edward Ayers, Vengeance and Justice: Crime and Punishment in the 19th-Century American South (New York, 1984), p. 243.

20 Preliminary analysis indicated, however, that the seasonal pattern of black lynching victims is very similar to the seasonal pattern of black lynching incidents. 


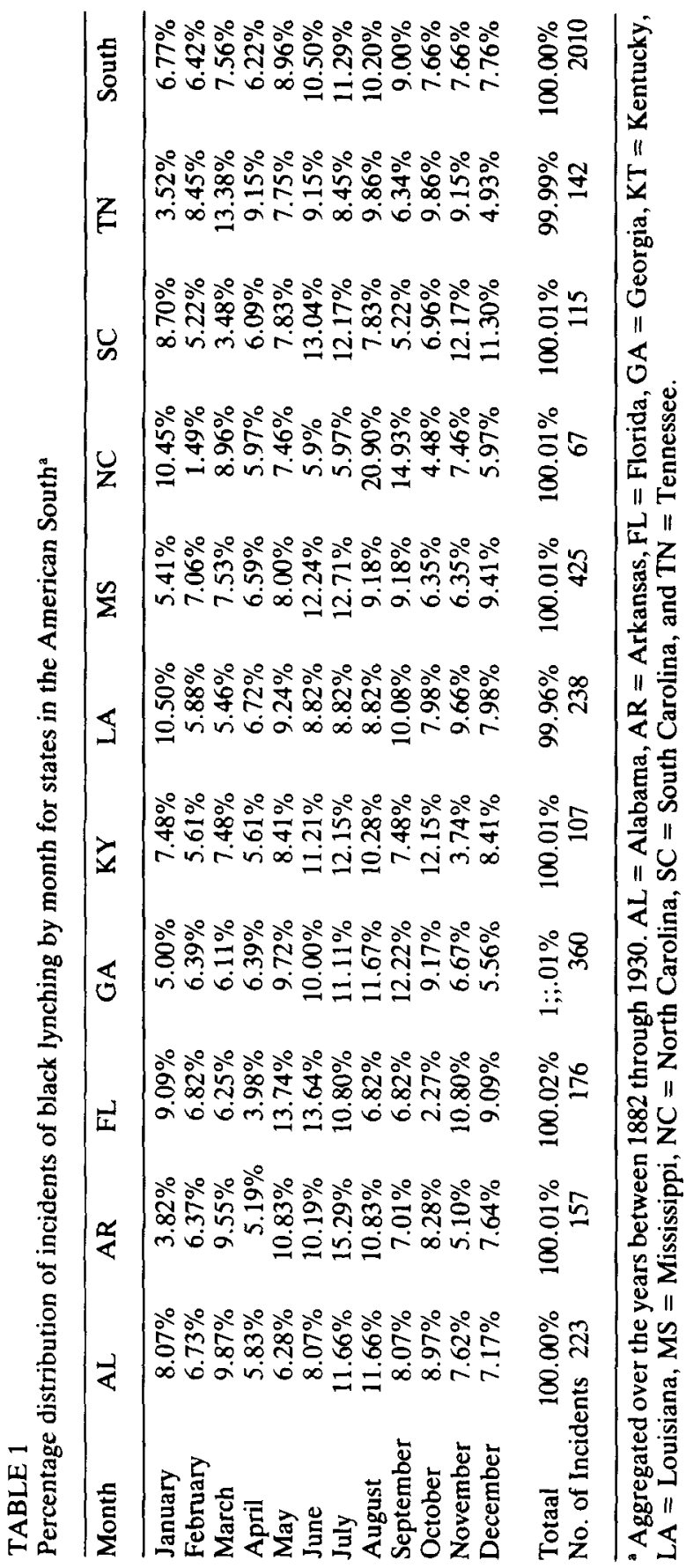


capture the seasonal nature of these lynchings we have plotted - in standard scores and as a percent of the annual monthly average - the monthly variation in black lynching incidents in the years between 1882 and 1930 in Figure 1. We have fit and superimposed a 4th-degree polynomial to highlight the general seasonal pattern of black lynchings. The seasonal fluctuation in black lynchings is quite evident: in the spring and winter months the number of incidents of mob violence was noticeably low, especially in the months of February and April, both of which were over $20 \%$ below the annual monthly average. ${ }^{21}$ After April, however, the frequency of mob violence increased - June, July, and August experienced over $22 \%$ more lynchings than the monthly average. The peak in lynching activity occurred in July which had $35 \%$ more lynching incidents than would be expected if there was no seasonality to anti-black mob violence. After July, the frequency of lynching declined through the winter. This pattern of lynchings is generally consistent with previous descriptions, and clearly reveals seasonal fluctuation in mob violence against blacks, with lynchings being more frequent in the warmer months and less frequent during the fall and winter. ${ }^{22}$ But, is there anything unique about this pattern?

As suggested earlier, it is possible that the patterns observed in Figure 1 may represent a confounding of two analytically separable, yet correlated patterns: the first is the seasonal trend of violent crime, in general (the "crime model"); the second is a seasonal pattern which is a function of the need to influence, if not control, the market for black labor in the South lethal mob violence, or the threat of violence, as well as non-lethal sanctioning of all varieties, is one mechanism for maintaining white control over the black agrarian labor force (the "labor control model"). The brutal treatment of some blacks at the hands of white mobs was a powerful message reinforcing the racial caste system by which blacks labored to produce wealth for elite whites. If this second seasonal periodicity exists, we expect that lynchings would become relatively more common during peak periods of labor demand when control over the black workforce is most crucial. ${ }^{23}$

It must be cautioned, however, that violence can be used to influence and

${ }^{21}$ For readers who place value on statistical tests for these kinds of data, we computed the $\chi^{2}$ comparing the observed number of lynching incidents in each month with the number expected under the assumption of no seasonality (a uniform distribution). The resulting $\chi^{2}$ was 72.81 with 11 degrees of freedom.

$n$ Ames, The Changing Character of Lynching; Southern Commission, Lynchings and What They Mean, p. 12.

${ }^{23}$ It could be argued that lynching was counter-productive because it removed labor from the supply pool by (1) k:lling able-bodied black workers, and (2) by encouraging black workers to migrate from areas of frequent mob violence. We believe that there is some evidence of the latter effect (see Tolnay and Beck, "Racial Violence and Black Migration", p. 113), but as for the former, the absolute number of blacks lynched would have represented a very small fraction of the total black labor force available for work. 


\section{FIGURE 1}

Monthly pattern of black lynching incidents in the American South, 1882-1930

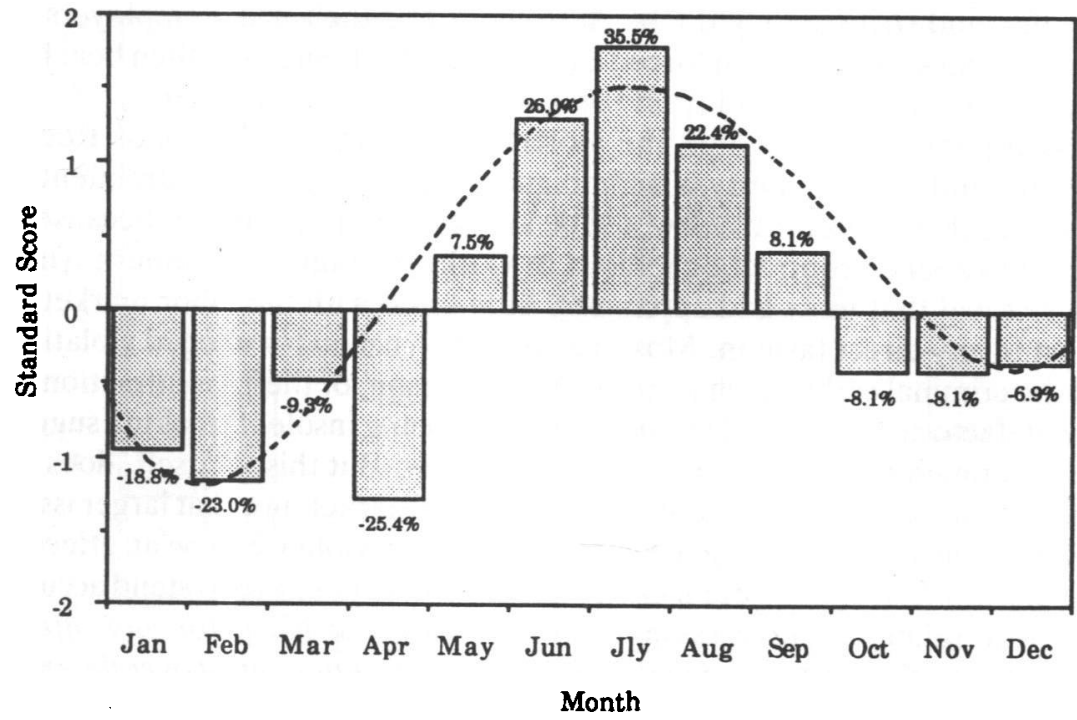

control labor in two different ways. The first, and most direct, is where mob action is aimed toward laborers refusing to work, workers who are organizing for collective bargaining, or workers who are otherwise trying to subvert the labor extraction process. A classic example of this direct action was the killing in Talbot County, Georgia, of Joseph Hardy, a roving blind black preacher. On a midsummer's night in 1909, a band of men forced Hardy from the home of William Cornaker in Talbotton. ${ }^{24}$ The mob spirited him away, and a few days later, Joseph Hardy's beaten body was discovered in a creek weighted down with a large stone. ${ }^{25}$ This blind preacher's "crime" had been to make speeches in the area urging local blacks to stop working for whites - the Columbus Enquirer-Sun newspaper characterized Hardy's sermons as "dangerous and incendiary". ${ }^{26}$ Clearly, Hardy's actions were viewed as threatening the supply of vitally needed black labor, and some whites believed this threat could not go unanswered. The state of Georgia provides us with yet another example of the use of violence to control labor. According to reports in the Atlanta Constitution, Robert Collins, a black

${ }^{24}$ Bill Winn, "Lynching on Wynn's Hill", Southern Exposure, Fall-Winter (1987), pp. $17-24$.

${ }^{25}$ Hardy was not the only one to die in this incident. Winn reports that Cornaker fought against the mob, killing one of them - a white planter named William Leonard. Later Cornaker turned himself in to the sheriff and was placed in jail. On 22 June, William Cornaker was taken from the jail by another white mob and lynched.

${ }^{26}$ Winn, "Lynching on Wynn's Hill", p. 18. 
resident of Oglethorpe County, Georgia, was lynched on 9 February 1894 for trying to entice black workers away from local plantations, and creating conflict and strife among the black servants and their white employers. A mob of masked white men forced Collins from his home, and then beat him unconscious. Collins died from these wounds a few hours later. ${ }^{27}$

While the motive behind the violence that ended the lives of Robert Collins and Joseph Hardy is unambiguous, it was relatively infrequent. It was rare that a specific black would be killed by indignant whites because he violated a labor contract or refused to work. Accounts of southern lynchings reveal that most had apparently little to do with the labor market, at least in any direct fashion. Most blacks were lynched for alleged violations of the criminal codes, such as murder, rape, arson, or theft, or infractions of the defacto code of racial etiquette, such as being insolent, making suggestive comments to white women, or being surly. But this, in itself, does not mean that violence had no impact on the labor market, nor that larger issues were not at stake. Quite to the contrary, for mob violence to be an effective means of social control of black labor, victims did not have to stand accused of work-related transgressions. The lynching of a black for any offense would have the effect of tightening or reinforcing white control over the entire local black population. For this reason, we suspect that the linkage between mob violence and the labor market was, for the most part, indirect and diffuse, as opposed to being direct and specific, yet this does not mean that it was any less real in its consequences.

\section{Adjusting for seasonal lethal violence}

In order to isolate the contributions of the "crime" and "labor control" models for the periodicity of lynching, we must "remove" that component of the seasonality of black lynching which is shared with other violent crimes. Optimally we would have liked to purge the monthly variation in lynching of any generalized pattern of violent crime which is unrelated to mob violence against blacks. This would require, in the ideal case, monthly data on the incidence, by race, of all violent crime in the South for the entire

${ }^{27}$ Blacks were not the only victims of mob violence against labor, however. In midJanuary 1923, E.C. Gregor, a white male, was hanged until dead from a railroad trestle in Harrison, Boone County, Arkansas. Mr. Gregor had been involved in a militant strike against the railroad and when questioned, he refused to identify those who might have been implicated in sabotaging the railroad. A few years later, Mrs. Ella May [Wiggins], a white female, was killed by a mob near Gastonia, North Carolina in early September 1929. She had joined a textile union and had been trying to arrange a mass meeting in Gastonia in support of her union's efforts to organize textile workers. Her efforts were not appreciated by textile employers and some of the local who may have feared for their jobs. 
FIGURE 2a

Monthly pattern of homicides in the American South, 1945-1950

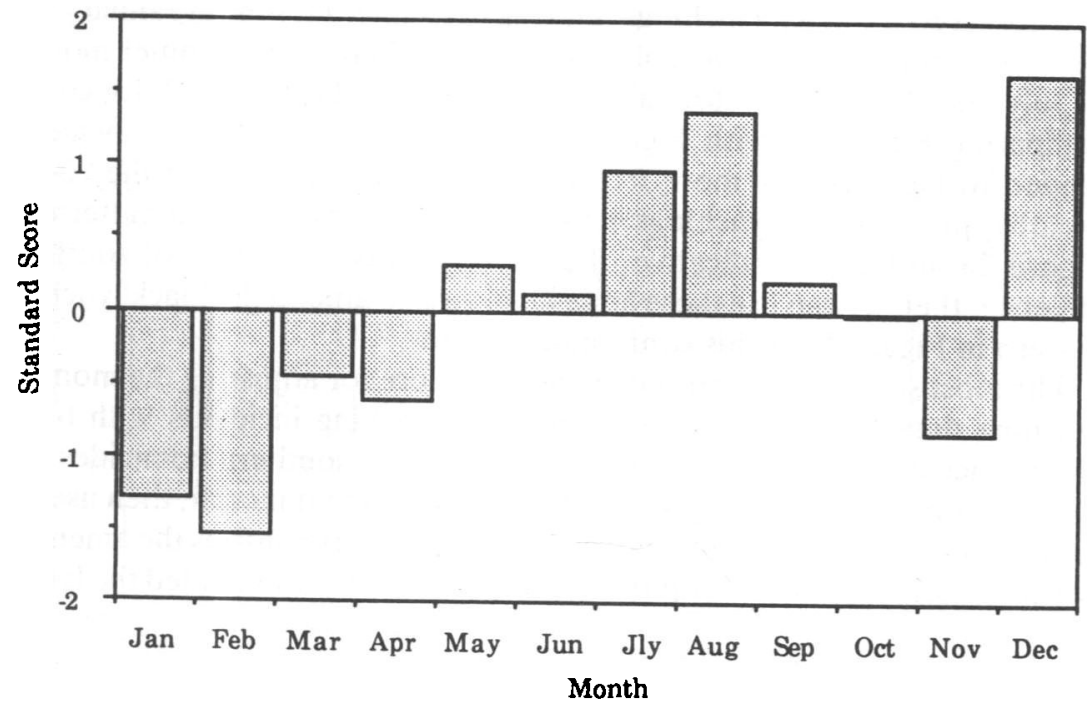

1882 to 1930 period. Unfortunately such data do not exist. In lieu of such "ideal" data, we used two proxies as indicators of generalized violence: the first is the seasonal pattern of southern homicides in our ten southern states over the 1945 tot 1950 period ${ }^{28}$ The second proxy for generalized violence is the seasonality of lynching incidents with white victims over the 1882-1930 span..$^{29} \mathrm{By}$ using the corresponding monthly pattern of southern homicides and monthly pattern of white lynchings as adjusting factors, the observed monthly pattern of black lynchings can be "corrected". If there is a persistence of a monthly pattern of lynching after this adjustment procedure, there would be evidence to suggest the operation of forces unique to the seasonality of black lynchings.

In Figure 2a we present the monthly pattern of murders - again in standard units - in the ten states for the years between 1945 and 1950, and in Figure $2 b$, the monthly pattern of white lynchings over the 1882 to 1930

${ }^{28}$ The source for these data are: National Office of Vital Statistics, Vital Statistics of the United States 1945-1949, Part II. Natality and Mortality Data for the United States Tabulated by Place of Residence (New York, 1968) and National Office of Vital Statistics, Vital Statistics of the United States. 1950. Volume III. Mortality Data (New York, 1968).

${ }^{29}$ During the $1882-1930$ period, there was a total of 2238 instances of lynching in the American South. Of these, the vast majority, 2010, were cases of black men, women, and children being killed by groups of whites. There were, however, 228 incidents involving white mobs and white victims. 
period. First, by comparing Figure 2 a with Figure 1, it is clear that there is some broad similarity between the seasonal pattern for homicides and the one observed for black lynchings. During the winter months of January and February, murders were notably less frequent than in the summer months of July and August, and the fall-winter month of December ${ }^{30}$ Likewise, comparing Figure $2 \mathrm{~b}$ with Figure 1 shows that white lynching incidents tended to be relatively more frequent in the summer than in the cooler months, just as black lynchings were.$^{31}$ If we take the seasonal patterns in Figure $2 \mathrm{a}$ and $2 \mathrm{~b}$ as indicative of a more pervasive pattern of southern violence, then we can use these additional data to amend the black lynching pattern in Figure 1 for this confounding factor. ${ }^{32}$

The most straightforward statistical procedure for adjusting the monthly lynching data is to regress the number of lynching incidents with black victims occurring each month on the frequency of southern homicides and frequency of white lynching incidents occurring in that month, then use the standardized residuals from this brief time-series regression as the amended lynching incident data. ${ }^{33}$ Employing this procedure, we amended the lynch-

${ }^{30}$ The pattern in Figure $2 \mathrm{a}$ is consistent with the general trend in homicides reported by Cheatwood ("Is There A Season for Homicide?", p. 302), including the spike in homicides in December.

${ }^{31}$ It is interesting to note that Figure $2 b$ shows that incidents of white lynchings were markedly above-average in December, which is comparable to the December spike in homicides in Figure 2a. However, as Figure 1 shows, black lynchings were slightly below average in December.

${ }^{32}$ As for the homicide data, we are, of course, assuming that the generalized pattern for the $1945-1950$ period would approximate any generalized pattern in the 1882-1930 period. There are no means for testing this assumption, but we do know that the 1945-1950 pattern of southern homicides is very similar to the $1970 \mathrm{~s}-1980 \mathrm{~s}$ pattern reported by Cheatwood ("Is There A Season for Homicides?", pp. 293-295) for the nation as a whole. Further, it is worth noting that research by H.C. Brearley shows that homicides in South Carolina from 1920 to 1924 display marked seasonality: with peaks occurring during periods of reduced farming work, " $[\ldots]$ one peak during the winter vacation and the other during the midsummer lay-by and camp meeting time", as cited by Vance, Human Factors in Cotton Culture, pp. 165-166. Even Quetelet's (A Treatise on Man, p. 90) analysis of French crime data of 1827-1828 show a rise in crimes against persons increasing in the summer months, declining in the early fall, then increasing again in December before declining in winter.

${ }^{33}$ That is, in terms of standardized residuals, the adjusted monthly lynching is:

Adjusted $Y_{i}=\left(Y_{i}-Y_{i}^{*}\right) / S_{e} \quad i=1,2, \ldots 12$

where $Y_{i}$ is the observed number of black lynching incidents occurring in the $i$ th month, $Y_{i}{ }^{*}$ is the predicted number of black incidents occurring in the $i$ th month based on a first-order moving-average regression with homicides and white lynchings as predictors, and $s_{e}$ is the square root of the mean square error. Expressed in terms of a percent, the adjusted frequencies are:

Adjusted $\% Y_{i}=100 \times\left[\left(Y_{i}-Y_{i}^{*}\right) /\left(Y_{i}^{*}\right)\right] \quad i=1,2, \ldots 12$

The only difference between these two forms is that in Eq. (1) the residuals are standardized by the root mean square; in Eq. (2) the residuals are expressed as a percent 
FIGURE 2b

Monthly pattern of white lynching incidents in the American South, 1882-1930

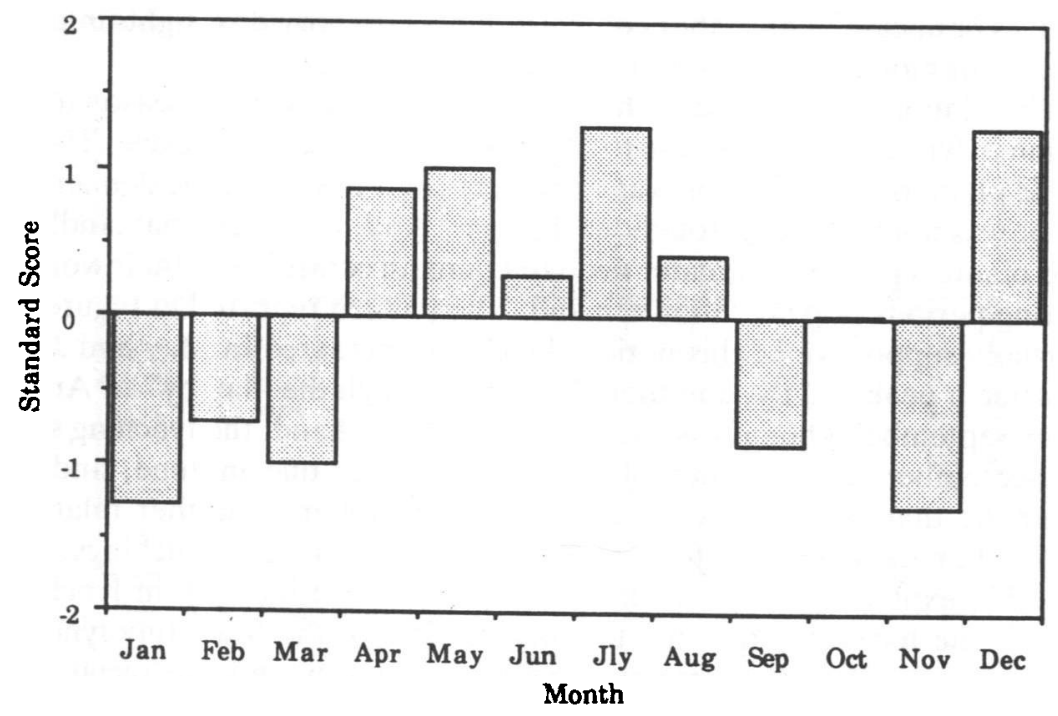

ing data reported in Figure 1, and the results of this adjustment are offered in Figure 3.

The revised pattern shows some differences from the original profile reported in Figure 1. In particular, in Figure 1 the spring and winter months (January through April) experienced a below average number of lynchings. In Figure 3, however, we find that after adjusting for the seasonal pattern of homicides and white lynchings, the frequency of blacks being killed by mobs in the winter and early spring months (January through April) did not deviate greatly from the annual monthly average. On the other hand, the summer season stands out as having a significantly above average number of lynchings - May, June, and July have, after controlling on the pattern of homicides and white lynching, from $15 \%$ to $19 \%$ more lynching incidents than would be expected otherwise. Furthermore, as can be seen in Figure 1, August was a month of significantly above average number of lynchings, but after adjusting for generalized violence, the lynching intensity in August falls below the annual monthly average (see Figure 3 ).

We believe that the adjusted pattern in Figure 3 indicates that there is a periodic component to black lynchings which exists over and above the general seasonal effects of lethal southern violence. In short, based on these data, we conclude that the "crime model" can not account, fully, for the of the predicted number of lynching incidents. The broad pattern of the adjusted lynchings is the same regardless of which form is adopted, either Eq. (1) or Eq. (2). 
monthly variation in southern black lynchings. But why should black lynchings be more common in summer, even in relation to other violent crimes such as homicide? The "labor control model" may provide insights into this persistent monthly variation in anti-black mob violence.

The "labor control model" hypothesizes that any unique seasonal variation in lynching could be due to the agricultural production cycle. That is, while plantation production was extremely labor intensive, the demand for labor was not uniform throughout the year. And, it is likely that landlords and planters perceived greater need to maintain control over their workers during periods of peak labor demand. The pattern reported in Figure 3 is partially supportive of this notion: lynchings increased in May and June, reached a peak in July, and then declined through the "lay-by" of August until September when it rose again. On the other hand, the lynching spike in September was considerably smaller than the one in June, and less dramatic than we expected. Furthermore, October - another relatively high labor demand month - experienced below average lynchings. One possible explanation for this lack of a pronounced increase in lynchings during the harvest is that the terroristic effect of the May-July lynching season was sufficient to maintain white supremacy and the racial caste system. This "carry-over" effect from the early summer may have reduced the need for lethal sanctioning during the cotton harvest season. ${ }^{34}$

Another confounding effect is the heterogeneous nature of agriculture in the South. While cotton was an important, if not essential, part of southern agriculture, some local areas were more dependent upon "King Cotton" than others. For example, $76 \%$ of the counties in Alabama, Georgia, Mississippi, and South Carolina were cotton-dependent, as compared with only $5 \%$ of the counties in Kentucky, North Carolina, and Tennessee. It is possible that by aggregating data across the entire South, that we have disguised or colored important seasonal patterns that may be related to differences in the agricultural production cycle.

\section{Dependency on cotton and violence against blacks}

To further explore the relationship between mob violence and the dependency upon cotton, we devided the counties of the South into two groups: those which were significantly dependent upon the production of cotton and those counties which were relatively less embedded in the cotton

${ }^{34}$ Another possible explanation is that during the harvest season, there was little need for sanctioning because field workers, farm tenants, and sharecroppers were more strongly motivated to work than in any other time in the production cycle. During the harvest their efforts had rather immediate economic payoff as the cotton was ginned and marketed. 
FIGURE 3

Adjusted seasonality of black lynching incidents ${ }^{\mathrm{a}}$

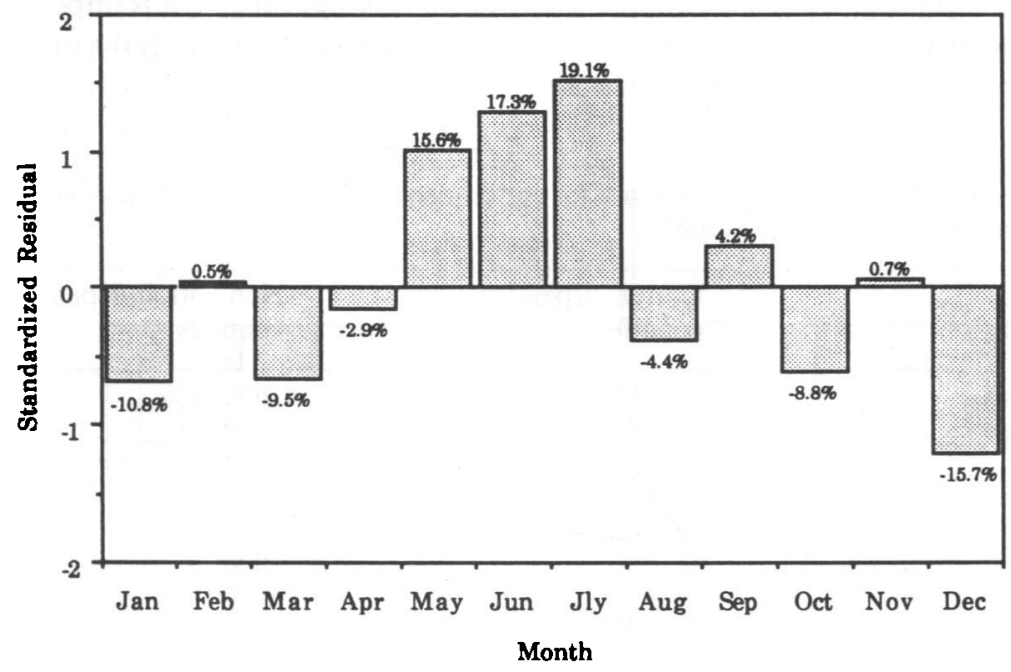

Adjusted for both the monthly pattern of southern homicides and monthly pattern of lynching incidents with white victims.

culture. ${ }^{35}$ For each group we tabulated the monthly pattern of black lynching incidents, and present these data in Table 2 as a percent distribution, and in Figure 4 in standard scores. As can be seen in Figure 4, there are both important similarities and significant differences between the cotton and non-cotton dependent counties in the seasonal pattern of mob violence: in both clusters of counties, lynching activity was average or below average during the winter and spring months (October through April), while the warm-weather months of May through September had an abundance of lynching incidents involving blacks. This is the same broad pattern we observed before. There is, however, an important dissimilarity.

The difference in the distribution of summer-time mob violence is striking. In cotton-dependent counties, the incidents of black lynchings were particularly frequent in the early and mid-summer, whereas in the non-

35 The criterion was the percentage of improved acreage dedicated to cotton production in 1899. Improved acreage includes land planted in crops, lying fallow, or in pastures. While the choice of cutting-point is somewhat arbitrary, we designated counties with more than $25 \%$ of acreage in cotton as cotton-dependent, and the non-cotton-dependent counties were those with less than $25 \%$. The median percent of acreage planted in cotton for the whole South was $16.8 \%$. It is worthwhile noting that $87.7 \%$ of the 326 cottondependent counties experienced at least one black lynching incident over the 1882-1930 period, as compared to $61.7 \%$ of the 483 non-cotton-dependent counties. The source of the cotton production data was the U.S. Department of the Interior, Census Reports, Agriculture, Parts I and II (Washington, 1902). 
cotton dependent areas, black lynchings were more common in the mid-to late-summer through September. While we believe this discontinuity in the seasonality of anti-black violence is substantively significant, it is important to "adjust" these trends for the seasonality of southern lethal violence before reaching any definite conclusions.

TABLE 2

Incidents of black lynchings by month for cotton-dependent and non-cotton-dependent counties in the American South ${ }^{\mathrm{a}}$

\begin{tabular}{lcc}
\hline Month & $\begin{array}{l}\text { Cotton-dependent } \\
\text { counties }\end{array}$ & $\begin{array}{l}\text { Non-cotton-dependent } \\
\text { counties }\end{array}$ \\
\hline January & $6.69 \%$ & $6.83 \%$ \\
February & $6.69 \%$ & $6.16 \%$ \\
March & $7.31 \%$ & $7.80 \%$ \\
April & $6.39 \%$ & $6.06 \%$ \\
May & $8.55 \%$ & $9.34 \%$ \\
June & $11.12 \%$ & $9.92 \%$ \\
July & $11.33 \%$ & $11.26 \%$ \\
August & $10.09 \%$ & $10.30 \%$ \\
September & $8.34 \%$ & $9.62 \%$ \\
October & $7.31 \%$ & $7.99 \%$ \\
November & $7.62 \%$ & $7.70 \%$ \\
December & $8.55 \%$ & $7.03 \%$ \\
Total & $99.99 \%$ & $100.01 \%$ \\
No. of Incidents & 971 & 1039 \\
\hline
\end{tabular}

a Aggregated over the years between 1882 and 1930. Cotton-dependent counties are those with more than $25 \%$ of acreage planted in cotton during the 1899 growing season. Non-cotton-dependent counties are those with less than $25 \%$ of acreage planted in cotton in the 1899 season.

Following the procedures explained earlier, we adjusted these raw seasonal trends for the patterns of southern homicides and seasonality of white lynchings. ${ }^{36}$ The residualized patterns are presented in Figure 5. Again, as was noted above, there were important similarities and dissimilarities in the seasonality of violence between those areas more heavily dependent upon cotton production and those less dependent. In both regions, black lynchings were markedly infrequent in December, above average in May, and displayed little seasonality during the winter, early spring, and early fall

${ }^{36}$ Since we did not have homicide data at the county level, we adjusted the seasonal pattern of lynching incidents of the cotton-dependent counties by the trend of homicides in the primary cotton-producing states (Alabama, Arkansas, Georgia, Mississippi, and South Carolina). Likewise, we adjusted the pattern of lynchings in the non-cottondependent areas by the trend in homicides in the less-cotton-producing states (Florida, Louisiana, Kentucky, North Carolina, and Tennessee). 
FIGURE 4

Comparison of seasonality of black lynching incidents between cotton-dependent and non-cotton-dependent counties

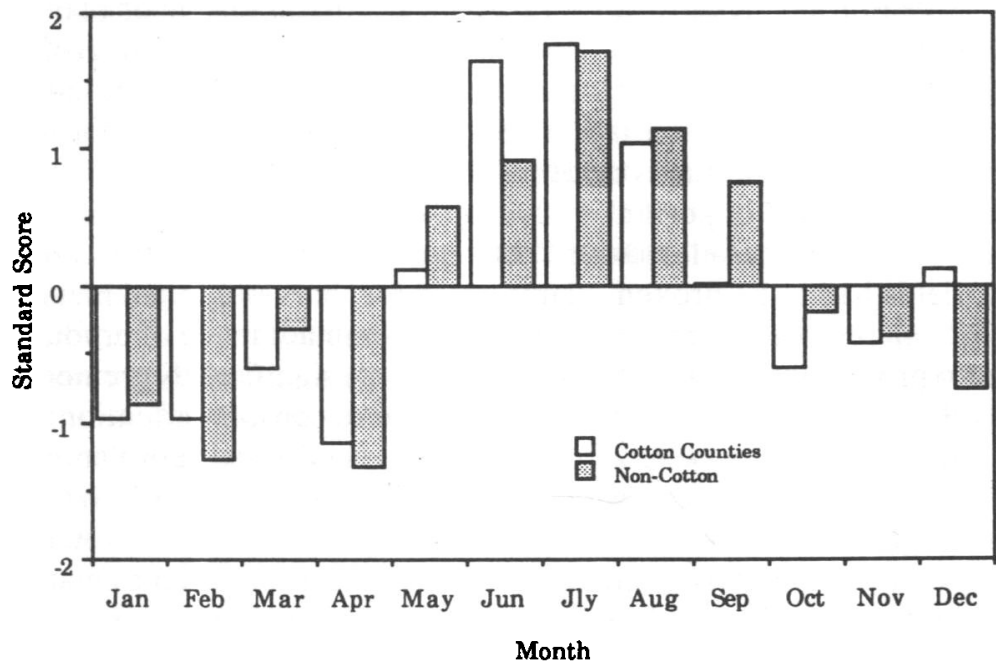

months. More germane to our argument, however, is the significant regional difference in the summer-time. After correcting the patterns for the seasonality of generalized violence, we find that June was a time of relatively high lynching activity in the cotton-dependent counties, whereas in the non-cotton regions of the South, June experienced only an average amount of lethal violence against blacks. The situation in July was dramatically reversed: in the non-cotton regions, July was a period of intense lynching activity, yet in the cotton-dependent South, July lynchings were only slightly elevated above the annual monthly average.

This regional difference in seasonality is significant because it is apparently linked to changes in the demand for farm labor. According to surveys tabulated by the U.S. Department of Agriculture, farm work in the major cotton producing southern states was the most demanding in May and June, which were two months of acute anti-black violence. On the other hand, July and August were periods of relative slack work in the cotton-culture, and as seen in Figure 5, two months of relatively less intense anti-black violence. ${ }^{37}$ This apparent association between the periodicity of labor demand in cotton-dependent regions and the frequency of mob violence against blacks is intriguing evidence supporting a labor control interpretation of southern racial violence.

${ }^{37}$ U.S. Department of Agriculture, Yearbook of the Department of Agriculture, 1920 (Washington, 1921), table 319, p. 823. 


\section{Violence and the flue-cured tobacco culture - an exploration}

The cultivation of "King Cotton" with its historical legacy of plantation production and chattel slavery, and later farm tenancy and sharecropping, left its distinctive mark on race relations in the South by molding the structure of caste and class relations. While the social and economic importance of cotton agriculture is undeniable, much of the South also had long cultivated a second important cash crop - tobacco. ${ }^{38}$ The rhythm of the "tobacco culture" paralleled the "cotton culture" to a point: in both regions, fields had to be broken, plants cared for, harvested, and marketed. And in both regions, sharecropping was the dominant mode of production. Tobacco production, however, required not only significantly greater labor inputs than did cotton cultivation, but also more constant attention: seedlings had to germinate, be tended to, and then cautiously transplanted into carefully prepared soil and watered, and afterward weeded. ${ }^{39}$ While the seedlings grew, hands were needed to cut and pile wood which would later be burned to flue-cure the ripe leaves. As the tobacco began to mature in June, field workers broke blossoming tops, pinched suckers, and pulled-off hornworms - all by hand. Later the first bottom leaves would begin to yellow and require "priming". "Priming" involved field workers pulling ripe leaves from the tobacco stalk, either by walking rows or riding behind a drawn wagon. The "primed" leaves were than tied to sticks by "stringers", and stored inside a tobacco "barn" for several days of flue-curing. After the curing process was completed, the individual leaves were then graded, tied into "hands", and later transported to market. Since the tobacco leaves did not mature at a constant rate, this process of priming, curing, and grading was repeated many times before season's end. However, the most intense

${ }^{38}$ This analysis of the tobacco culture applies only to the flue-cured, bright leaf tobacco of the Carolinas, and some parts of Georgia and Florida. The burley tobacco cultivated in Kentucky and Tennessee had a significantly different production cycle. See Charles K. Mann, Tobacco: The Ants and the Elephants (Salt Lake City, 1975), pp. 27-43, and W.W. Garner et al., "History and Status of Tobacco Culture", Yearbook of the Department of Agriculture, 1922 (Washington, 1923), pp. 395-468. In addition to tobacco, two other cash crops were particularly important in some areas of the South: rice and sugar. We ignore these two agricultures in this paper, but see Daniel (Breaking the Land, pp. 39-61), and Rupert Vance (Human Geography of the South: A Study in Regional Resources and Human Adequacy (Chapel Hill, 1935), pp. 214-225) for discussions of these crops, and their importance to the South.

${ }^{39}$ For discussions of the tobacco culture and its production cycle, see Daniel, Breaking the Land, pp. 23-38; Garner et al., "History and Status of Tobacco Culture", pp. 395-468; Mann, Tobacco: The Ants and the Elephants, pp. 40-43; Phillips, Life and Labor in the Old South, pp. 112-115; and Vance, Human Geography of the South, pp. 205-213. 
labor demand was in late July and August. Earlier in this century, southern sociologist Rupert Vance lamented that tobacco was "[...] truly a crop which wears out men and land". 40

Thus, in comparison to cotton, the production cycle of flue-cured tobacco differed in two significant ways: (1) tobacco was significantly more labor intensive, and (2) it required more constant attention, meaning that tobacco crops were not "laid-by" like cotton. This meant that while August was a period of relative inactivity for cotton farmers - slack demand for labor - it was a time of growing labor demand for tobacco producers. Again, the "labor control model" would predict lynchings to be more frequent when demand is strong.

To explore the relationship between anti-black violence we followed procedures similar to those employed earlier by identifying counties which were most dependent upon flue-cured tobacco cultivation. ${ }^{41}$ Next, we tabulated the seasonal distribution of black lynching incidents within these tobacco-dependent counties, and then adjusted this distribution for the seasonal periodicity of homicides. ${ }^{42}$ In Figure 6 we contrast the adjusted seasonal pattern of lynching between tobacco-dependent and cotton-dependent counties. ${ }^{43}$

${ }^{40}$ Vance, Human Geography of the South, p. 212.

${ }^{41}$ The notion of "tobacco-dependent" may be slightly exaggerated. Areas growing flue-cured tobacco were far less dependent upon a single crop than were regions specializing in cotton cultivation. For example, for the 1899 growing season, the two largest producers of tobacco in the Carolinas were Rockingham and Stokes counties in North Carolina. Together these two counties produced over 15 million pounds of tobacco in 1899 , yet only $14 \%$ of their improved acreage was dedicated to tobacco production. The cotton-dependent counties were quite different: during the 1899 season, in each of the prime cotton producing states, many counties devoted over $50 \%$ of their improved land to cotton cultivation - in one Mississippi county, more than $80 \%$ of its improved acreage was planted in cotton. Clearly, the "tobacco-dependent" regions were significantly less dependent on their cash crop than were the "cotton-dependent" areas on their's.

Because of the differences between the intensity of tobacco and cotton cultivations, we used a lower cutting-point to define the tobacco-dependent counties: we defined any county in North Carolina, South Carolina, Georgia or Florida as "tobacco-dependent" if more than $3 \%$ of its improved acreage was devoted to tobacco cultivation in 1900 . By this definition, North Carolina had 19 tobacco-dependent counties, South Carolina three, and Georgia and Florida had none. Of these tobacco-dependent counties, only 14 had lynchings with at least one black victim.

${ }_{42}$ Since the overwhelming number of tobacco-dependent counties were in North Carolina, we used the seasonal pattern of homicides between 1945 and 1950 in North Carolina as our proxy for generalized violence in the tobacco culture. Because of the very limited number of white lynchings that took place in these tobacco-dependent counties (only two), it was not possible to include the seasonality of white lynchings as an additional proxy, and control, for generalized violence in the coastal tobacco culture.

${ }^{43}$ The pattern for the entire South in Figure 6 is the same pattern originally offered in Figure 3. 
From this figure it is obvious that the seasonality of anti-black violence was markedly different between the counties of the "cotton culture" and those of the "tobacco culture". In cotton-dependent areas - after controlling on the periodicity of generalized violence - the peak lynching period encompassed May and June, whereas in the tobacco-dependent counties, there were major peaks in January and again in August, and significantly smaller increase in September. ${ }^{44}$ We are at a loss for a "labor control" interpretation of the January spike, but the August increase in black lynchings is consistent with the idea that violence may have been used to influence and control black labor in the tobacco-dependent counties of the South during the harvest.

\section{Conclusion}

In the American South during the years 1882 to 1930 the lynching of blacks for "crimes" against whites was a common spectacle, yet mob violence was not random in either time or geography. In this paper we have explored one fragment of the lynching picture, the seasonal pattern of black southerners dying at the hands of their white neighbors. Like many other violent crimes, lynchings were more frequent in the hot summer months than in cooler seasons. We believe this seasonality was not a direct reflection of climate, but rather due to changing labor requirements over the agricultural production cycle - mob violence was more frequent during times of stronger labor demand than during slack periods. While the manifest function of lynchings might well have been to rid the white community of offending blacks who violated the moral order, we suggest that the latent function was to tighten the reins of control over the black population, especially during times when whites most needed black labor to work fields of cotton or tobacco.

Yet, support for the labor control model in our findings was not as clean as might have been hoped. While there was a general correspondence between lynchings and the peak of pre-harvest work in the cotton fields,

${ }^{44}$ It must be cautioned, however, that the seasonal trend for the tobacco-dependent counties is based on far fewer counties and lynching incidents than was the seasonal pattern for the cotton-dependent counties. The seasonal trend for the flue-cured tobacco is based on only twenty-five incidents of black lynchings distributed over four counties in the Carolinas. The trend for the cotton-dependent South, however, is based on 971 lynchings with black victims distributed over 286 southern counties. This means that the seasonal pattern in the tobacco counties would be highly sensitive to very small changes in the distribution of lynching incidents. 
FIGURE 5

Comparison of adjusted seasonal patterns of black lynching incidents between cottondependent and non-cotton-dependent counties ${ }^{\mathrm{a}}$

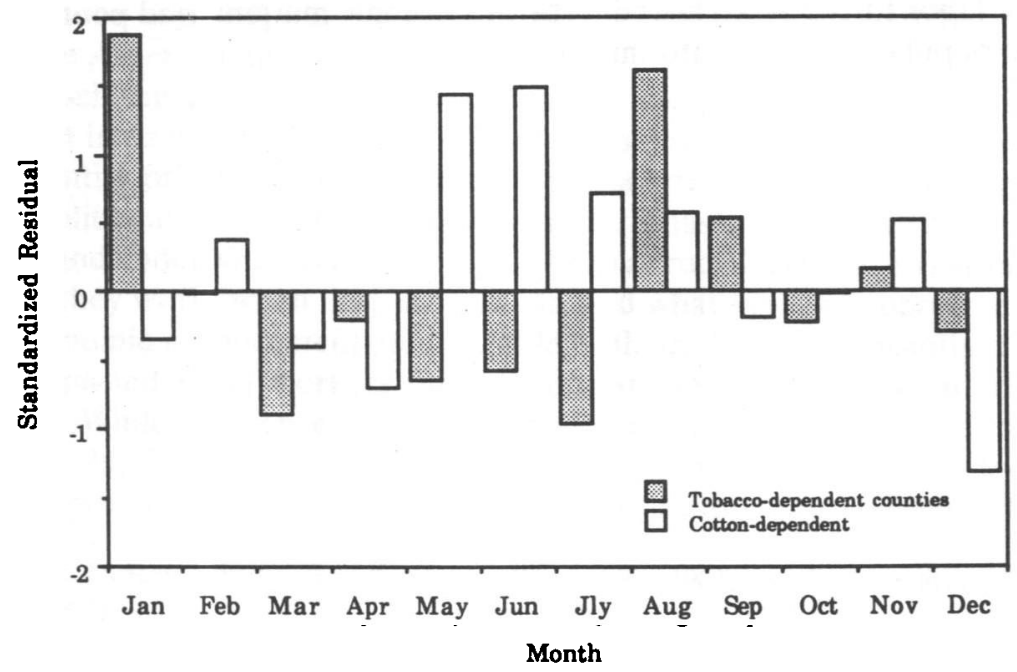

a Adjusted for both the monthly pattern of southern homicides and monthly pattern of lynching incidents with white victims.

\section{FIGURE 6}

Comparison of adjusted monthly patterns of black lynching incidents in tobacco-dependent and cotton-dependent counties ${ }^{a}$

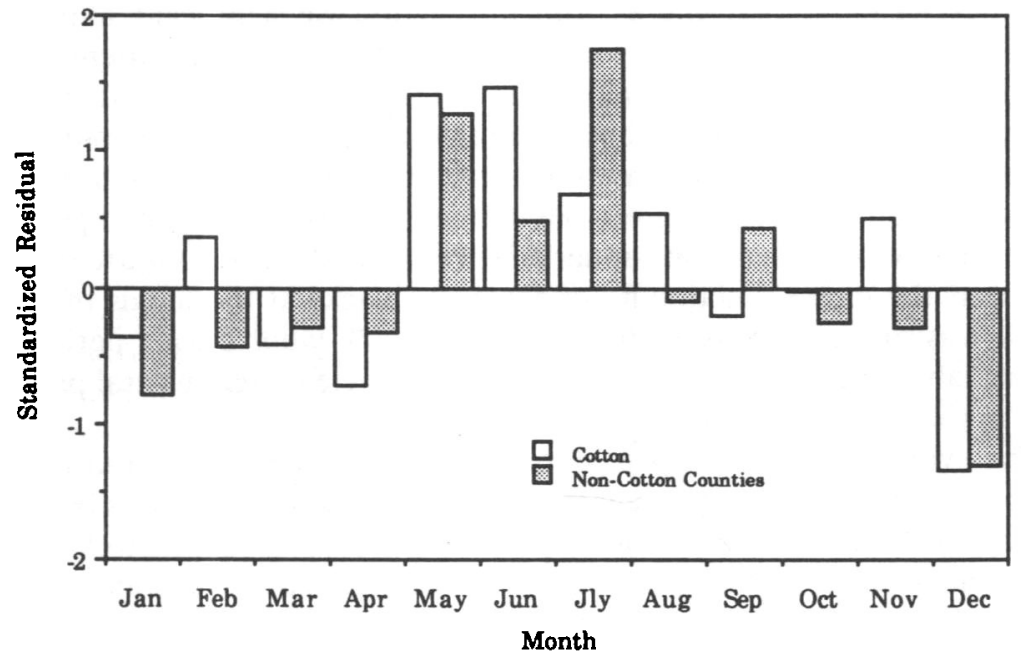

${ }^{a}$ Cotton-dependent pattern adjusted for seasonality of homicides and lynchings with white victims; tobacco-dependent pattern adjusted for seasonality of homicides only. 
there was no strong evidence of a similar correspondence between mob violence and the intense labor demands of the cotton harvest. When the South was disaggregated into cotton-dependent and non-cotton-dependent counties, we found that where cotton production was significant, anti-black violence was most common in May and June; in those regions where cotton was less important economically, anti-black violence peaked later in the summer season. As for the tobacco culture of the Carolinas, we found that black lynchings were relatively more common during the tobacco harvest in August, and to a lesser degree, September, but we also found a peculiar increase in mob violence in January. Nevertheless, our results are suggestive that the lethal sanctioning of southern blacks at the hands of white mobs was one mechanism for influencing black labor during periods of strong labor demand which was linked to the cycle of agricultural production in the American South.

The evidence presented here also hints at some potentially fruitful avenues of inquiry for future research. First, the marked differences between the cotton-dependent and non-cotton-dependent regions, as well as the differences between the tobacco-dependent and cotton-dependent counties, indicate that agricultural specialty sharply influenced the nature of social control within local communities. In that sense, the patterns which emerged in this analysis may be an understatement of the true relationship between agricultural production and lethal violence, given the relative high level of aggregation of the data used here.

Second, the "labor control model" of seasonality requires greater elaboration and exploration. For example, how did landlords and planters use racial violence to their best advantage, without driving-off their valued black labor force? And, how did the increasingly marginalized poor white rural population factor into this process? 